\title{
Growth and Fluctuations in the Output of Major Crops in Pakistan, 1950-51 to 1979-80
}

\author{
MAHMOOD HASAN KHAN and AHMAD SAEED SIDDIQUi*
}

\begin{abstract}
Since the crop environment in Pakistan is still greatly influenced by the vagaries of Nature, it is important to separate this effect from the true process of crop growth. Attempts to capture the large random fluctuations from the trend line by using a single variable for weather are not fruitful at all. In the absence of a composite index of weather, the indirect method used in this study allows identification of normal and abnormal years, which can then be used for forecasting or even insurance (planning) purposes.
\end{abstract}

\section{INTRODUCTION}

Crop production is subject to wide fluctuations in most of the underdeveloped countries, as man's control of his natural environment is fragile. Studies of growth in crop output tend to concentrate on trends, excluding fluctuations from them. Thus probably a very important aspect of real growth is lost. The estimation of trends is greatly confounded by seemingly random fluctuations, induced mainly by weather, from these trends. Measurement of trends and fluctuations should be of interest to policy-makers and researchers alike. They can help in identifying the extent to which technology may have overcome the vagarious behaviour of Nature. Also, computation of trend rates of growth with and without the extreme fluctuations can provide meaningful insights into the process of crop forecasting and planning.

The conventional method of measuring trends is to fit trend equations to raw data and to calculate the standard error of estimate. For trends from which the fluctuations are small and infrequent, this method may be satisfactory. However, if fluctuations are large and frequent, affecting the trend significantly, the estimated trend is likely to present a distorted image of the real phenomenon. One way to circumvent this problem is to include weather as a proxy for large fluctuations. There

*The authors are Professor of Economics, Simon Fraser University, Canada and Senior Vice President, United Bank Limited, Karachi. This paper was completed when the first author was Visiting Professor, Applied Economics Research Centre, University of Karachi. 
are at least three problems here. ${ }^{1}$ Firstly, in relatively large areas, such as a province or even a district, weather cannot be averaged out. Secondly, rainfall alone cannot be a proper measure of the influence of weather on crop growth, and information on other equally important components of weather is usually not available or difficult to incorporate. Finally, weather may not be the only cause of fluctuations, and a method which attributes all variations to weather is clearly unsatisfactory.

It is usually assumed that residuals from the trend are like random variables, but it need not be true. An understanding of the nature of the residuals is necessary for several reasons. For one thing, this will identify the effects of fluctuations on the trend itself. Secondly, the structure of past growth can be studied aıd, in combination with other changes, it can generate useful information on the growth process itself. Finally, the trend estimates derived after separating the effects of wide fluctuations can be used to forecast and even plan crop production.

In Pakistan, analysis of growth of crop output has been limited to only a few studies. $^{2}$ Almost no attempt has been made to estimate the effects of fluctuations on trend rates of growth in crop output. The inclusion of a weather proxy to eliminate fluctuations from the trend in time-series data on crop output has not clarified the issues. The problems of forecasting have been confounded by the choice of an almost simplistic model and misspecification of variables. This study will highlight the effects of fluctuations on the trend rates of growth of crop output in Pakistan, with emphasis on major crops in the Punjab and Sind provinces. Further, using trend rates of growth in crop yields and acreage, it will shed some light on the inter-crop and interregional differences in the process of growth during a thirty-year period.

\section{METHOD AND DATA}

The conventional formula for estimating the trend line in crop production is the $\log$ normal form, though linear and other forms have also been used. ${ }^{3}$ Accordingly, for each crop/region, we use the following regression equation to estimate the

${ }^{1}$ The direct method of including weather has been discussed in detail by B. Oury [4] The author has demonstrated that selecting only one of the elementary weather factors (say rainfall) as a single variable is unrealistic.

${ }^{2}$ In Pakistan, few studies have been published on forecasting models, including weather (rainfall) as a separate variable. The first study was by S. K. Qureshi [6]. The next two studie: on wheat in the Punjab were done by B. A. Azhar, M. Ghaffar Chaudhry, and M. Shafique. Basec on the the same authors estimated wheat ouspu on the model developed by them in [2], paper, the same authors estimated wheat outpu forecast for Punjab in a subsequent paper [1]. The model suffers from several flaws. For on thing, the authors have used only a linear form of the regression equation. Then there is the serious problem of misspecification of the weather variable. In a subsequent paper, Chaudhry and Kemal [3] used again a linear production function, with rainfall, to forecast wheat output is Punjab. They did not give a reasonable explanation for using the linear form, except that the CES and Cobb-Douglas forms gave low $\mathrm{R}^{2}$ values. However, they admitted that they did not test if the linear form related the dependent and independent variables in the "best possible manner" (p. 222).

${ }^{3}$ This technique has been explained by V. M. Rao, M. V. Nedkarni and R. S. Deshpande trend rate of growth in output:

$$
\ln 0=a+b T
$$

where 0 is the total output of a particular crop, $\mathrm{T}$ is the trend variable, and ' $\mathrm{a}$ ' and ' $b$ ' are the regression coefficients. The trend rate of growth over the thirty-year period will then be $\left(a_{\text {tilog }} \mathrm{b}-1\right) \times 100$. However, a valid estimate of the trend rate of growth cannot be based on a regression of Equation (1) for all years, as it does not separate the effects of fluctuations which may themselves be determining the location of the trend line.

The basic idea here is to classify the period for which the trend is being estimated into 'normal', 'good', and 'bad' years. The distinction of normal from good and bad years can be made by drawing upper and lower bands on the trend line estimated for all years. The years falling above them upper band can be regarded as good years and those under the lower band as bad years. The years inside the two bands are then called normal years. The band lines can be drawn on each side of the trend line at a 10 -percent interval. The choice of the 10-percent interval on each side is much like the choice one makes on confidence levels in statistical analysis.

The data for this exercise are for wheat, rice, cotton, and sugarcane from the Punjab and Sind separately. The period is from 1950-51 to $1979-80$. The results for Pakistan are also reported, but in most cases they reflect the large share of the Punjab in the acreage and output of these crops.

\section{RESULTS AND INTERPRETATIONS}

In Table 1, we identify normal, good and bad years for output of each crop in Pakistan and two of its provinces. These are based on regressing Equation (1) estimated by the Ordinary-Least-Squares method. The significance of these years (or sub-periods) will become apparent in the discussion which follows.

The estimated values of ' $b$ ' coefficients, along with their standard errors and $\mathrm{t}$-ratios, for the trend lines for all years as well as for normal years are given in Table 2. The t-ratio, obtained by dividing the standard error of ' $b$ ' into the estimated vlaue of ' $b$ ', can be said to indicate the 'stability' of the trend coefficient 'b'. All t-ratios are significant at $\alpha=0.01$. Also, the values of $\overline{\mathrm{R}}^{2}$ and $\mathrm{t}$-ratios improve in all cases for regressions on data for normal years, i.e. excluding good and bad years from the regressions gives a better fit of the trend equation. The interest here is in the trend rates of the growth of output of crops, $\left(\operatorname{antilog}_{e} b-1\right) \times 100$, for all years and for normal years. The t-ratios for normal-year regressions are lower than for all years for every crop, indicating that the growth rates obtained after excluding the good and bad years from the regression equations are more stable. The rates of growth for normal years are higher than for all years for wheat and rice in 
both provinces. The same holds for cotton in the Punjab but not in Sind. In the case of sugarcane, the rates for all years are higher than for normal years. The implication is that use of regressions for all years leads to overestimation of rates of growth of output of sugarcane in both provinces and of cotton in Sind, and their under-estimation for wheat and rice in both provinces and for cotton in the Punjab.

Wheat, rice and sugarcane have had higher and more stable growth rates of output than cotton. However, wheat seems to have done better in Sind and rice in the Punjab. Among the major crops, cotton had the lowest rates, and these rates were also the least stable. The output of sugarcane grew at a higher rate in Sind and it was also the more stable between the two provinces. As indicated later, the rapid expansion of the output of sugarcane in Sind resulted from an expansion of the area devoted to it, as the yield level declined somewhat.

Looking more closely at normal, good and bad years for each crop in Table 1, we find several interesting features of the growth experience. For wheat, all the good and bad years were experienced in the period preceding the onset of the Green Revolution in the late Sixties: good years in the early Fifties and all bad years in the early to mid-Sixties. The Seventies were the normal years, reflecting the impact of high-yielding varieties with water and fertilizer. Similarly, for rice, all the good and bad years were experienced before the introduction of the IRRI varieties in the late Sixties, and the Seventies were the normal years. Cotton and sugarcane were subject to more frequent and large fluctuations. For cotton, the Fifties and the Sixties (except 1964-65) were the normal years, and most of the fluctuations took place in the Seventies. For sugarcane, the late Fifties and early Seventies can be regarded as normal years, and all of the good years were in the Sixties while the bad years were mostly in the early Fifties and the middle or late Seventies.

The analysis so far has suggested that the growth rates of output have been underestimated for wheat and rice in all areas, but for cotton only in Punjab, and overestimated for sugarcane. Secondly, the fluctuations, presumably induced mainly be weather, were reduced in wheat and rice in the Seventies, reflecting the increasing role of technology, which was not the case with cotton and sugarcane. This last point is brought into greater relief in the trend rates of the growth of crop yields shown in Table 3. The t-ratios are significant at $\alpha=0.01$ in all cases. The values of $\overline{\mathrm{R}}^{2}$ and $\mathrm{t}$-ratios are quite high for wheat and rice comparatively lower for cotton and sugarcane, and quite low for sugarcane in Sind. Growth rates of yields are higher and more stable for wheat and rice than for cotton and sugarcane. Yield improvements in sugarcane were the lowest and negative in Sind. Wheat, rice and cotton seem to have done better in Sind and sugarcane in the Punjab. The case of sugarcane in Sind is particularly shocking.

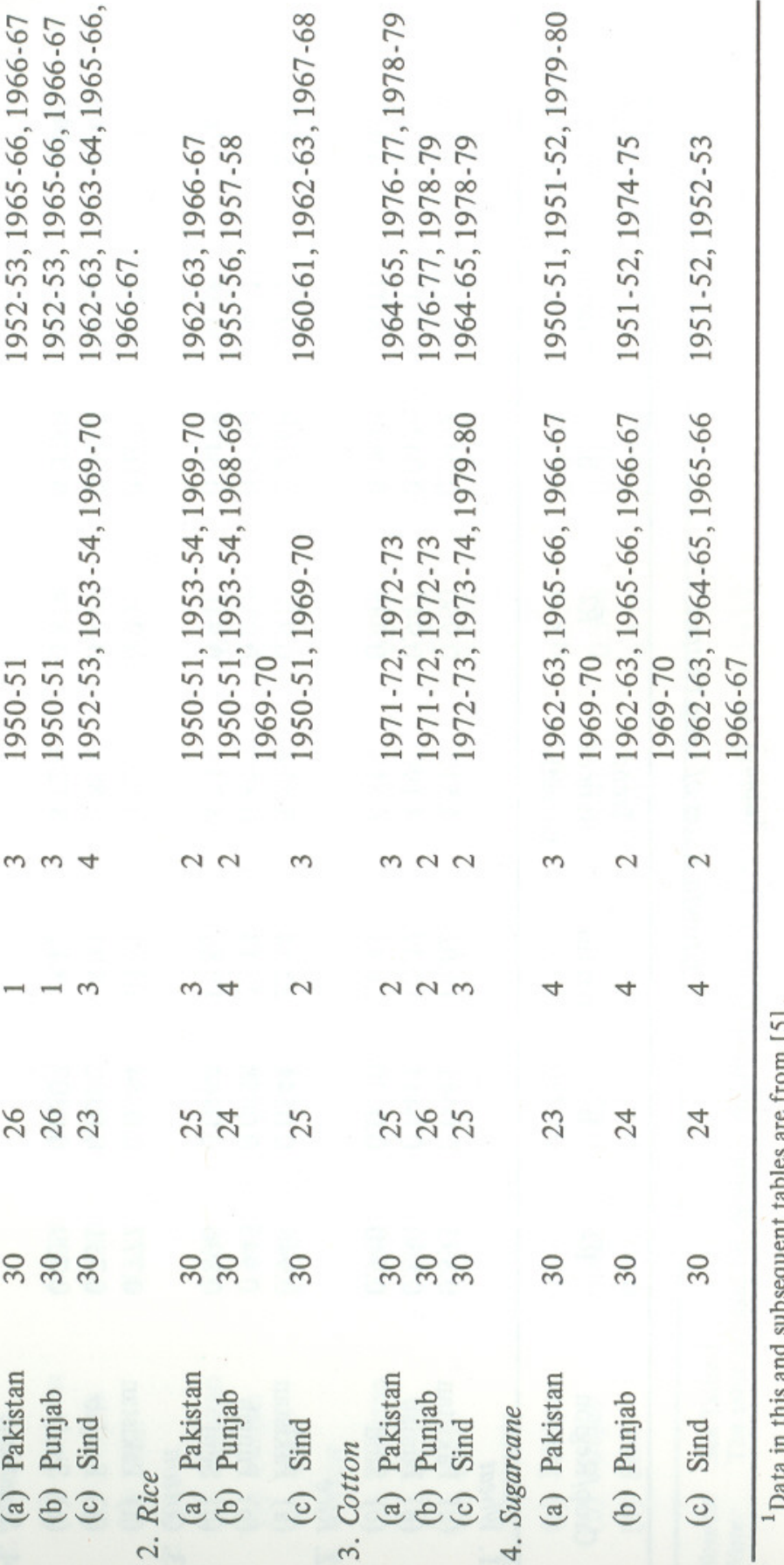


Table 2

Growth Rates of Crop Output

\begin{tabular}{lcccccccc}
\hline Crop/Region & $\overline{\mathrm{R}} 2$ & $\mathrm{~b}$ & $\mathrm{t}$-ratio & $\begin{array}{c}\text { Trend } \\
\text { Rate of } \\
\text { Growth }\end{array}$ & $\overline{\mathrm{R}}$ & $\mathrm{b}$ & $\mathrm{t}$-ratio & $\begin{array}{c}\text { Trend } \\
\text { Rate of } \\
\text { Growth }^{2}\end{array}$ \\
\hline $\begin{array}{l}\text { 1. Wheat } \\
\text { (a) Pakistan }\end{array}$ & 0.893 & 0.0441 & 15.62 & $4.51 \%$ & 0.960 & 0.0458 & 24.37 & $4.69 \%$ \\
$\quad$ (b) Punjab & 0.860 & 0.0411 & 13.39 & $4.19 \%$ & 0.947 & 0.0426 & 21.07 & $4.35 \%$ \\
(c) Sind & 0.940 & 0.0630 & 21.43 & $6.51 \%$ & 0.985 & 0.0647 & 38.07 & $6.68 \%$ \\
2. Rice & & & & & & & & \\
(a) Pakistan & 0.946 & 0.0544 & 22.54 & $5.59 \%$ & 0.975 & 0.0569 & 30.71 & $5.85 \%$ \\
(b) Punjab & 0.945 & 0.0658 & 22.43 & $6.80 \%$ & 0.981 & 0.0660 & 34.62 & $6.82 \%$ \\
(c) Sind & 0.896 & 0.0464 & 15.86 & $4.75 \%$ & 0.946 & 0.0475 & 20.48 & $4.86 \%$ \\
3. Cotton & & & & & & & & \\
(a) Pakistan & 0.777 & 0.0344 & 10.11 & $3.50 \%$ & 0.902 & 0.0371 & 14.90 & $3.77 \%$ \\
(b) Punjab & 0.731 & 0.0362 & 8.92 & $3.68 \%$ & 0.847 & 0.0392 & 11.82 & $3.99 \%$ \\
(c) Sind & 0.739 & 0.0307 & 9.11 & $3.12 \%$ & 0.829 & 0.0289 & 10.82 & $2.94 \%$ \\
4. Sugarcane & & & & & & & & \\
(a) Pakistan & 0.882 & 0.0545 & 14.77 & $5.60 \%$ & 0.937 & 0.0509 & 18.06 & $5.22 \%$ \\
(b) Punjab & 0.869 & 0.0518 & 13.92 & $5.32 \%$ & 0.930 & 0.0501 & 17.45 & $5.13 \%$ \\
(c) Sind & 0.874 & 0.0996 & 14.24 & $10.47 \%$ & 0.936 & 0.0937 & 18.40 & $9.83 \%$ \\
\hline
\end{tabular}

Source: See Table 1.

Notes: $\quad{ }^{1}$ These are based on data for all years, from 1950 to 1980.

${ }^{2}$ These are based on data for normal years only.

(The regression equation on which this table is based is $1 \mathrm{n} 0=\mathrm{a}+\mathrm{bT}$ )

Table 3

Growth Rates of Crop Area and Yield

\begin{tabular}{|c|c|c|c|c|c|c|c|c|}
\hline \multirow[b]{2}{*}{ Crop/Region } & \multicolumn{4}{|c|}{ Growth Rate of Crop Area } & \multicolumn{4}{|c|}{ Growth Rate of Yield / Hectare } \\
\hline & $\overline{\mathrm{R}}^{2}$ & $\mathrm{~b}$ & t-ratio & $\begin{array}{c}\text { Trend Rate } \\
\text { of Growth (\%) }\end{array}$ & $\overline{\mathrm{R}}^{2}$ & $\mathrm{~b}$ & t-ratio & $\begin{array}{l}\text { Trend Rate } \\
\text { of Growth }\end{array}$ \\
\hline \multicolumn{9}{|l|}{ 1. Wheat } \\
\hline (a) Pakistan & 0.924 & 0.0177 & 18.81 & 1.78 & 0.806 & 0.0264 & 11.01 & 2.68 \\
\hline (b) Punjab & 0.894 & 0.0612 & 15.64 & 1.63 & 0.774 & 0.0249 & 10.02 & 2.52 \\
\hline (c) Sind & 0.882 & 0.0255 & 14.77 & 2.58 & 0.838 & 0.0376 & 12.30 & 3.83 \\
\hline \multicolumn{9}{|l|}{ 2. Rice } \\
\hline (a) Pakistan & 0.952 & 0.0267 & 23.93 & 2.71 & 0.816 & 0.0276 & 11.38 & 2.80 \\
\hline (b) Punjab & 0.940 & 0.0429 & 21.39 & 4.38 & 0.757 & 0.0229 & 9.55 & 2.32 \\
\hline (c) Sind & 0.792 & 0.0126 & 10.56 & 1.20 & 0.785 & 0.0338 & 10.35 & 3.44 \\
\hline \multicolumn{9}{|l|}{ 3. Cotton } \\
\hline (a) Pakistan & 0.849 & 0.0179 & 12.82 & 1.81 & 0.573 & 0.0165 & 6.32 & 1.66 \\
\hline (b) Punjab & 0.811 & 0.0211 & 11.18 & 2.13 & 0.478 & 0.0151 & 5.25 & 1.52 \\
\hline (c) Sind & 0.525 & 0.0101 & 5.75 & 1.01 & 0.623 & 0.0206 & 7.00 & 2.08 \\
\hline \multicolumn{9}{|l|}{ 4. Sugarcane } \\
\hline (a) Pakistan & 0.872 & 0.0430 & 14.11 & 4.40 & 0.607 & 0.0115 & 6.77 & 1.15 \\
\hline (b) Punjab & 0.813 & 0.0387 & 11.67 & 3.95 & 0.594 & 0.0131 & 6.58 & 1.32 \\
\hline (c) Sind & 0.908 & 0.1079 & 16.90 & 11.40 & 0.276 & -0.0084 & -3.48 & -0.83 \\
\hline
\end{tabular}

Source: See Table 1.

Note: The table is based on regression equations (i) $\log \mathrm{A}=2+\mathrm{bT}$ and (ii) $\log \mathrm{Y}=2+\mathrm{bT}$. 
More interesting are the changes in yield per hectare of these crops. ${ }^{4}$ The impressive growth in the yield of wheat in the Punjab and Sind started with the adoption of dwarf seeds in the late Sixties (1968-1969). It is also interesting to note that, contrary to the popular notion that the vigour of new seeds has been reduced considerably, the upward movement of the yield level did not slow down in recent years. Another important feature is that the (local) wheat yield rose in the Punjab but not in Sind in the pre-Green Revolution period. The reason for this could be the development of additional water through tubewells in the Punjab in the late Fifties and early Sixties.

Rice yields also showed a sharp upward break in the late Sixties in both the provinces. However, the upward trend has remained quite strong in Sind, but less apparent in Punjab. Here the difference between the two provinces can probably be explained by the fact that while the IRRI varieties formed the bulk of all rice grown in Sind, the Basmati rice dominated in the Punjab.

The story of cotton yields is a sad one, and is consistent with the trend rates of growth observed earlier. The yield levels remained almost static in the Fifties, rose somewhat in the Sixties, but fell dramatically in the Seventies. Lack of improvement in cotton technology, particularly the poor quality of seed and limited disease resistence or control, kept the production of cotton exposed to the moods of Nature.

The case of sugarcane is also quite disturbing. Its yield level in the Punjab remained almost stagnant in the Fifties, improved significantly in the Sixties, and again became stagnant in the Seventies. In Sind, the yield level has been either stagnant or declining over the years. The yield of sugarcane has been subject to wide fluctuations, due mainly to changes in weather and poor state of technology. At the same time, sugarcane has been claiming probably the two most scarce of the country's resources (land and water) for the greater part of the year.

Trend rates of growth in crop area are shown in Table 3. Again, the t-ratios are significant at $\alpha=0.01$ in all cases. The values of $\overline{\mathrm{R}}^{2}$ and $t$-ratios are quite high, except for cotton in Sind. Acreage of cotton in Sind has shown the slowest and least stable growth rate. Growth rate of acreage was the highest for sugarcane in Sind, and was followed by those for rice and sugarcane in the Punjab.

It is also possible to decompose the "sources" of growth of the output of major crops during the thirty-year period. It will identify the effects of yield and area on increases in output of each crop. The results are shown in Table 4. As expected, most of the contribution to the additional ouput of wheat and IRRI rice has been made by yield per hectare, reflecting the joint impact of new seeds, fertilizer and water. Since Basmati rice dominates in the Punjab, only about one-third of the additional output there was due to the yield effect. The contributions of area and yield to additions in the output of cotton differ markedly

\footnotetext{
${ }^{4}$ The yield data are given in [5]
}

between the Punjab and Sind. The area effect is pronounced in the former and the yield effect in the latter province. These differences are consistent with the evidence from field studies on yields and use of inputs in these provinces. The additional output of sugarcane in both provinces has been due largely to the area effect, and it is particularly evident in Sind. It seems that a favourable price structure, and the menace of water-logging and salinity in some areas, precluding profitable cultivation of other crops, have induced farmers to allocate more area to sugarcane than is socially profitable.

Table 4

Contribution of Yield and Acreage in Growth of Crop Output

\begin{tabular}{lcccc}
\hline & \multicolumn{3}{c}{ Percentage Contribution in Growth of Output } \\
\cline { 2 - 5 } Crop/Region & Yield & Acreage & Intraction Effects & Total \\
\hline 1. Wheat & & & & \\
(a) Pakistan & 59.42 & 39.47 & 1.11 & 100.00 \\
(b) Punjab & 60.14 & 38.90 & 0.96 & 100.00 \\
(c) Sind & 58.83 & 39.63 & 1.54 & 100.00 \\
2. Rice & & & & \\
(a) Pakistan & 50.09 & 48.48 & 1.43 & 100.00 \\
(b) Punjab & 34.12 & 64.41 & 1.47 & 100.00 \\
(c) Sind & 72.42 & 26.52 & 1.06 & 100.00 \\
3. Cotton & & & & \\
(a) Pakistan & 47.43 & 51.71 & 0.86 & 100.00 \\
(b) Punjab & 41.30 & 57.88 & 0.82 & 100.00 \\
(c) Sind & 66.67 & 32.37 & 0.96 & 100.00 \\
4. Sugarcane & & & & \\
(a) Pakistan & 20.54 & 78.57 & 0.89 & 100.00 \\
(b) Punjab & 24.81 & 74.25 & 0.94 & 100.00 \\
(c) Sind & -7.93 & 108.88 & -0.95 & 100.00 \\
\hline
\end{tabular}

Source: See Table 1.

\section{CONCLUSION AND POLICY IMPLICATIONS}

Since the crop environment in Pakistan, as in many other underdeveloped countries, is still dominated by the capricious behaviour of Nature, it is imperative to separate this effect from the true process of growth in crop production. 
Attempts to capture the large random fluctuations from the trend line by using a single variable for weather, such as rainfall, are not fruitful at all. In the absence of a composite index of weather, the indirect method used in this note for estimating the trend without fluctuations allows identification of normal and abnormal years, which can then be used for forecasting or even insurance (planning) purposes.

A closer study of the normal crop years with changes in the yield levels has brought into sharper relief the differential impact of technology on various crops. The decomposition of the yield and area effects on additional output has highlighted the fact that for cotton and rice Basmati in the Punjab and for sugarcane in the Punjab and Sind most of the additional output was obtained through the expansion of area under these crops. The policy implication, at least in the case of sugarcane in Sind and of cotton in the Punjab, is that research and extension services should be intensified to improve production technology, including new inputs and cultivation practices. At least in the case of sugarcane in Sind, land and water are perhaps being diverted to a crop whose private profitability far exceeds the social gains due mainly to a favourable price structure.

\section{REFERENCES}

1. Azhar, B. A., M. Ghaffar Chaudhry and M. Shafique. "A Forecast of Wheat Production in the Punjab for 1973-74”. Pakistan Development Review. Vol. XIII, No. 1. Spring 1974. pp. 106-112.

2. Azhar, B. A., M. Ghaffar Chaudhry and M. Shafique. "A Model for Forecasting Wheat Production in the Punjab". Pakistan Development Review. Vol. XII, No. 4. Winter 1973. pp. 407-415.

3. Chaudhry, M. Ghaffar, and A. R. Kemal. "Wheat Production under Alternative Production Functions”. Pakistan Development Review. Vol. XIII, No. 2. Summer 1974. pp. 222-225.

4. Oury, B. "Allowing for Weather in Crop Production Model Building". Journal of Farm Economics. Vol. 47, No. 2. May 1965. pp. 270-283.

5. Pakistan. Ministry of Food, Agriculture and Cooperatives. Food and Agriculture Division (Planning Unit). Agricultural Statistics of Pakistan (for 1975, 1977, 1979 and 1980). Islamabad.

6. Qureshi, S. K. "Rainfall, Acreage and Wheat Production in West Pakistan: A Statistical Analysis”. Pakistan Development Review. Vol. IV, No. 4. Winter 1964. pp. 173-203.

7. Rao, V. M., M. V. Nedkarni and R. S. Deshpande. "Measurement of Growth and Fluctuations in Crop Output - An Approach based on the Concept of Non-Systematic Component”. Indian Journal of Agricultural Economics. Vol. 35, No. 2. April-June 1980. pp. 21-30. 